\title{
Public conceptions of the impact of oral health on quality of life
}

\author{
Population based norming of the UK oral health related quality of life measure (OHQoL-UK॰) \\ C. McGrath and R. Bedi Br Dent J 2002; 193: 521-524
}

\section{Objectives}

The aims of this study were to establish normative age-gender values for the UK oral health related quality of life measure $\left(\mathrm{OHQOL}_{-} \mathrm{UK}^{\odot}\right)$ in Britain and to provide a local reference for its interpretation. In addition, to identify key factors associated with oral health related quality of life in the UK.

\section{Materials and methods}

A national survey conducted with the assistance of the Office for National Statistics involving a random probability sample of 2,718 households. Participants were interviewed about their oral health status. The impact of oral health on quality of life was measured using the 16 item OHQoL-UK measure.

\section{Results}

The response rate was $68 \%(1,838 / 2,718)$. The majority $(75 \%$, $1,378 / 1,838)$ perceived their oral health as affecting their life quality and did so across a wide range of domains. Age-gender norm values are presented. Variations in OHQoL-UK scores were apparent in relation to socio-demographics: age $(\mathrm{P}<0.05)$, social class $(\mathrm{P}<0.01)$, and self-reported oral health status: number of teeth possessed $(\mathrm{P}<0.01)$.

\section{Conclusions}

The impact of oral health on the life quality of Britons was substantial, in both positive and negative ways and associated with socio-demographic and oral health (self-reported) factors. National norm values presented should provide a reference source for meaningful interpretation of similar data and local studies.

\section{IN BRIEF}

- National study of the impact of oral health on the quality of life.

- The majority of the British public perceived their oral health as affecting their life quality.

- Age and gender norms for the $\mathrm{OHO} \mathrm{OL}_{-} \mathrm{UK}^{\odot}$ measure are presented.

- Age, social class and number of teeth appear to be key factors influencing the impact oral health status has on life quality.

\section{COMMENT}

The impact of oral health and oral disease on quality of life is an area of rapid growth in research and conceptual development. Over the last decade investigators have been concerned with the development of research tools and the examination of inequalities in oral health related quality of life between groups defined by age, social class and ethnicity. This research has clearly established that the impact of the oral cavity on life quality can be determined reliably and validly and that the presence of dental and oral disease has a negative impact on the quality of life, including difficulties in eating, socialising, and other activities. ${ }^{1}$

Recently however, researchers, including Professor Bedi and Dr McGrath, have suggested that simply assessing the negative impact of dental disease on quality of life fails to appreciate the very positive contribution that the healthy dentition makes upon everyday life. The development of the OHOoL-UK is an attempt to incorporate both the negative and positive aspects of quality of life, building upon new conceptual models of health. ${ }^{2}$

Such an approach is not without controversy. Are the positive aspects of oral health generally appreciated? It could be argued that people tend not to notice the role our teeth have in, say, speech until something goes wrong. McGrath and Bedi's data provide an interesting, if tentative, insight into this question. Examining the percentage of respondents who indicated that they felt their 'teeth, gums and/or false teeth' had 'no effect' on the specific $\mathrm{OHOoL}-\mathrm{UK}$ items we find that this ranged from $37 \%$ for 'comfort' to $78 \%$ for 'finances'. The example of finances would fit well with the idea that the healthy dentition is not normally associated with any impact on quality of life. In this case the absence of a negative is not necessarily perceived as a positive for all people. For other items though, it is clear that teeth are seen as having a positive effect - a good example is 'appearance' where $58 \%$ report a positive effect. There would appear to be individual variation in the extent to which oral health is seen as associated with impact. It might be expected that this would relate to the complexity of an individual's understanding of 'oral health. ${ }^{3}$ There is still a great deal of research to be carried out in this area, the authors are to be congratulated for their groundbreaking work.

\section{J. T. Newton, Senior Lecturer, Psychology in Relation to Dentistry GKT Dental Institute}

1. Slade G D (Ed.) Measuring Oral Health and Quality of Life. Chapel Hill: University of North Carolina Dental Ecology, 1997

2. World Health Organisation. International Classification of Functioning and Disability: ICIDH-2. Geneva: WHO, 1998.

3. Corrigan M, Newton J T, Gibbons D E, Locker D. The Mouth-body split: conceptual models of oral health and their relationship to general health among ethnic minority groups resident in South East England. Community Dent Health, 2001; 18: 42-46. 